\title{
Overinflated behavioural energetics: using dynamic body acceleration to accurately measure behaviour duration and estimate energy expenditure
}

\author{
Anthony A. Robson ${ }^{1,2, *}$, Robert P. Mansfield ${ }^{2}$ \\ ${ }^{1}$ LabexMER, UMS 3113 CNRS, Institut Universitaire Européen de la Mer, Université de Brest, Rue Dumont D'Urville, \\ 29280 Plouzané, France \\ ${ }^{2}$ Faculty of Life Sciences, University of Manchester, Michael Smith Building, Oxford Road, Manchester M13 9PT, UK
}

\begin{abstract}
Data loggers that measure acceleration are regularly used to quantify the behavioural energetics of animals. Calculating dynamic body acceleration (DBA) by smoothing acceleration data using a necessarily long-running mean of e.g. $\geq 1 \mathrm{~s}$ (the DBA method) is not appropriate for determining behaviour duration. In fact, the DBA method results in the elongation of behaviour durations (mean $\pm 95 \%$ CI behaviour duration elongation for scallops [n $=10$ animals] and humans [ $\mathrm{n}=10$ free-ranging aquatic biologists]: $508.5 \pm 277.2$ and $19.3 \pm 1.1 \%$, respectively) and consequently an overestimation of energy expenditure (mean $\pm 95 \%$ CI activity metabolic rate overestimation: $212.5 \pm 48.0$ and $6.12 \pm 0.34 \%$, for scallops and humans, respectively; overall metabolic rate overestimation: $91.1 \pm 29.9$ and $4.18 \pm 0.20 \%$, for scallops and humans, respectively). Behaviour duration elongation is of greatest significance when behaviour durations are short (minimum, mean and maximum single behaviour duration for scallops and humans recorded in this study: 0.12 and $0.37,0.40$ and 8.04, 0.84 and $185.73 \mathrm{~s}$, respectively). Overestimation of the duration of behaviours naturally causes errors in the calculations of behavioural time-energy budgets for all species that move intermittently, as demonstrated for scallops, crabs, 'amphibious' signal crayfish and humans. Furthermore, behaviours of any duration should be accurately detected, quantified and when appropriate, the behaviour type should be identified. The R package BEnergetix can quickly calculate accurate invertebrate and vertebrate behavioural time-energy budgets from acceleration, metabolic rate and environmental data.
\end{abstract}

KEY WORDS: Behaviour - Activity $\cdot$ Energy expenditure $\cdot$ Ecology $\cdot$ Accelerometer $\cdot$ Accuracy $\cdot$ $\mathrm{R}$ package $\cdot$ Crayfish $\cdot$ Scallop $\cdot$ Crab $\cdot$ Human

\section{METHODS AND DISCUSSION}

The daily time spent active and inactive are key factors in animal ecology and have important energetic consequences. Thus, behaviour duration should be measured accurately. The quantification of animal behavioural energetics from data recorded by animalattached acceleration loggers is rapidly increasing in popularity (Brown et al. 2013). These accelerometers

*Corresponding author: a.a.robson@outlook.com measure the change in velocity of an animal's body over time and allow the fine-scale measurement of behaviour and body postures, unlimited by visibility, terrain, climate, observer bias or the scale of space use. Unfortunately, accelerometer data processing can cause the elongation of behaviour duration and thus an underestimation of resting duration in a behavioural time budget (e.g. Halsey \& White 2010). Can the accelerometry technique be improved? Here

() The authors 2014. Open Access under Creative Commons by Attribution Licence. Use, distribution and reproduction are unrestricted. Authors and original publication must be credited. 
we show how the accelerometry technique has and has not been used to accurately measure behaviour duration. Furthermore, we show that a consequence of the elongation of behaviour duration is the overestimation of energy expenditure.

In Robson et al. (2012), individual scallops Pecten maximus were instrumented with miniature datalogging devices; these recorded acceleration in 3 axes $(0-6 g)$, gape angle $\left({ }^{\circ}\right)$ via a calibrated Hall sensor (Robson et al. 2009), depth (m) and temperature $\left({ }^{\circ} \mathrm{C}\right)$, all at $16 \mathrm{~Hz}$ with 22-bit resolution continuously for 24 to $36 \mathrm{~h}$. Fig. 1 illustrates the occasional shortburst activity typically exhibited by scallops.

A derivative of dynamic body acceleration (DBA) such as the vector sum of dynamic body acceleration
(VeDBA) can be calculated from tri-axial acceleration data recorded by a logger instrumented to a subject animal $\left(\operatorname{VeDBA}(g)=\sqrt{\left(a^{2}{ }_{x}+a^{2}{ }_{Y}+a^{2}{ }_{z}\right)}\right.$ where $a_{X \prime}$ $a_{y}$ and $a_{z}$ are dynamic acceleration values derived from raw $X_{1} y_{1} Z$ acceleration data (Gleiss et al. 2011)). Such data represent the acceleration recorded by the logger owing to the dynamic movement of that individual (Wilson et al. 2006). DBA can be used to assess the behaviours of the animal and can also be calibrated with rate of energy expenditure. Measurements of DBA in scallops enabled Robson et al. (2012) to measure the effects of anthropogenic disturbance on the behaviour and energy expenditure of farmed individuals. To interpret scallop behaviour from the data, the entire DBA and gape angle data set was (a)

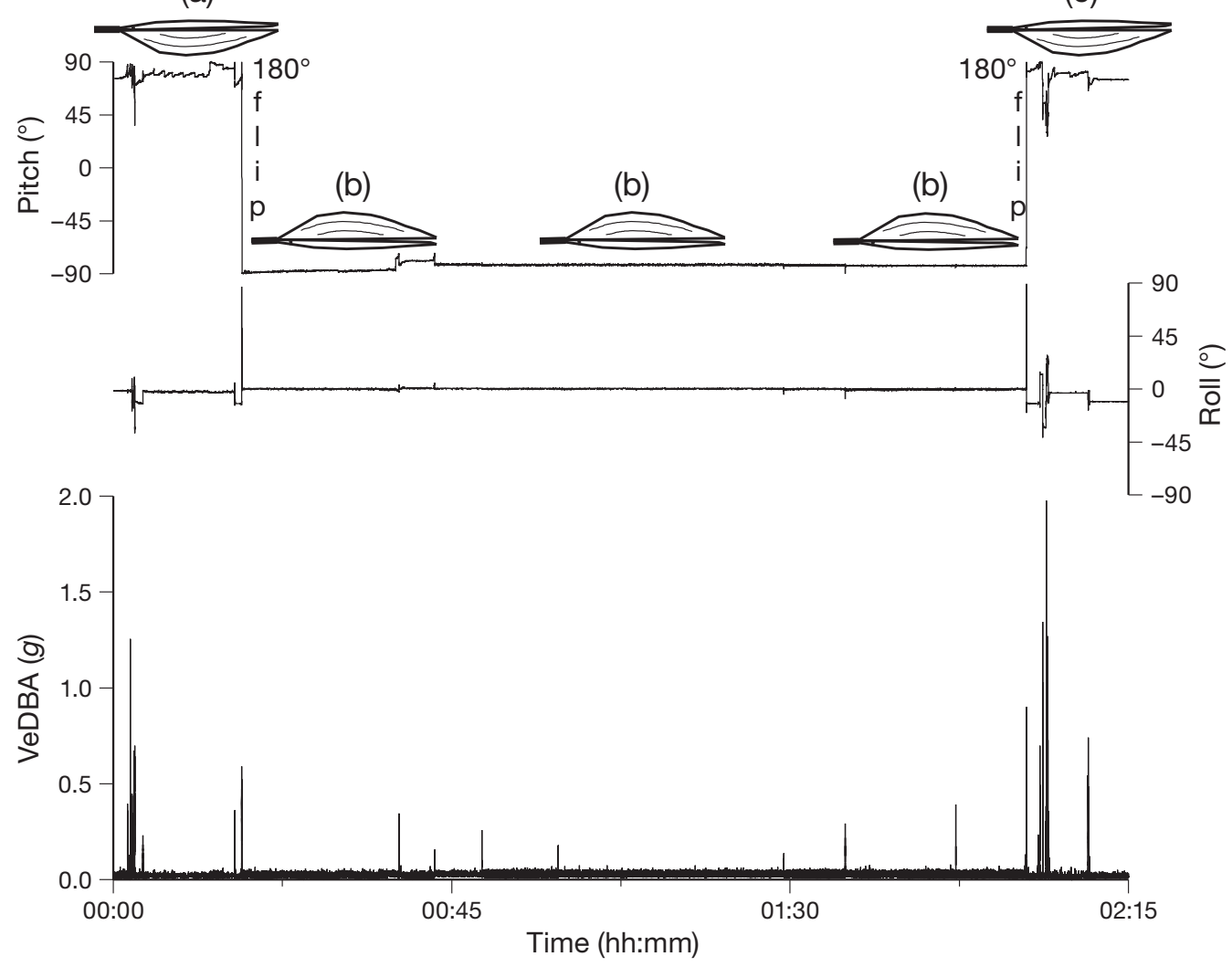

Fig. 1. Scallop Pecten maximus short-burst activity including two $180^{\circ}$ flips. Top panel: body pitch derived using the equation:

$$
\arctan \left(\frac{\text { static heave }}{\sqrt{\text { static surge } \text { static sway }^{2}}}\right) \text {. }
$$

Scallops (a) to (c) indicate body posture when the individual is stationary. Initially the scallop is in its typical posture in a depression in the seafloor sediment with the upper (left) valve uppermost (a) and the scallop subsequently flips $180^{\circ}$ using rapid valve adduction followed by abduction events $\left(2\right.$ to $\left.3 \mathrm{~s}^{-1}\right)$ so that its upper valve is resting on the seafloor sediment (b), before flipping back to its initial posture (c). Middle panel: body roll derived using the equation:

$$
\arctan \left(\frac{\text { static sway }}{\sqrt{\text { static surge }^{2}+\text { static heave }^{2}}}\right) \text {. }
$$

Bottom panel: vectorial summation of scallop dynamic body acceleration (VeDBA) 
plotted against time, and signatures within the trace indicating active behaviours were selected manually. DBA was selected only where a corresponding rapid change in gape angle (Robson et al. 2007) was recorded. From the manually selected DBA trace for each behaviour, the duration of the behaviour was calculated, along with the mean DBA to estimate energy cost. Furthermore, the behaviour 'type' was identified by eye both from the DBA and depth trace for each behaviour and by viewing the associated infrared video recordings. This manual analysis produces accurate behavioural time budgets, but is labour intensive for large data sets and impractical when analysing similar data recorded at high frequency from hundreds of animals. Furthermore, the Hall sensor needed to record gape angle is not a standard feature of commercial data loggers that record (tri-axial) acceleration e.g. the AXY-2 data logger (TechnoSmArt), which can record at high resolution (cf. Robson et al. 2009) for 6 wk. Thus, there is considerable value in an automated system for analysing acceleration data and without the need for the quantification of gape angle.

It is important to note that the method for calculating DBA by smoothing acceleration data using a necessarily long running mean of e.g. $\geq 1 \mathrm{~s}$ (Shepard et al. 2008) (the DBA method) is not appropriate for determining behaviour duration. In fact, the DBA method results in the elongation of behaviour duration (mean $\pm 95 \% \mathrm{CI}$ behaviour duration elongation for scallops ( $\mathrm{n}=10$ animals) and humans ( $\mathrm{n}=10$ freeranging aquatic biologists): $508.5 \pm 277.2$ and $19.3 \pm$ $1.1 \%$, respectively) and consequently an overestimation of energy expenditure (mean $\pm 95 \%$ CI activity metabolic rate overestimation: $212.5 \pm 48.0$ and 6.12 $\pm 0.34 \%$, for scallops and humans, respectively; overall metabolic rate overestimation: $91.1 \pm 29.9$ and $4.18 \pm 0.20 \%$, for scallops and humans, respectively; see Supplement 1 at www.int-res.com/articles/suppl/ b021p121_supp.pdf); elongating a single crayfish, scallop and human behaviour by 22.4 (8), 2.28 (59) and 1.04 (18) s (\%), respectively (Fig. 2). Fig. 2 shows that behaviour duration elongation is of greatest significance when behaviour durations are short (minimum, mean and maximum single behaviour duration for scallops and humans recorded in this study: 0.12 and $0.37,0.40$ and $8.04,0.84$ and $185.73 \mathrm{~s}$, respectively). It is important to emphasise that the overestimation of the duration of behaviours is an issue for all species, that move intermittently.

Unfortunately, one root mean square (rms) DBA value (e.g. Spivey \& Bishop 2013) cannot be output from each row of raw $x, y, z$ acceleration because the rms is calculated from $\mathrm{N}$ dynamic acceleration samples $\left(a_{x 1} \ldots a_{x n}, a_{y 1} \ldots a_{y n}, a_{z 1} \ldots a_{z n}\right)$. For example if $N=$ 75 (3 s when recording at $25 \mathrm{~Hz}$ ) then rms DBA can be calculated:

$$
\begin{aligned}
a_{1} & =\left(a_{x 1}{ }^{2}+a_{y 1}{ }^{2}+a_{z 1}{ }^{2}\right) / 3 \\
a_{2} & =\left(a_{x 2}{ }^{2}+a_{y 2}{ }^{2}+a_{z 2}{ }^{2}\right) / 3 \\
a_{3} & =\left(a_{x 3}{ }^{2}+a_{y 3}{ }^{2}+a_{z 3}{ }^{2}\right) / 3 \\
\ldots a_{n} & =\left(a_{x n}{ }^{2}+a_{y n}{ }^{2}+a_{z n}{ }^{2}\right) / 3 \\
\text { rms DBA } & =\sqrt{\left(a_{1}+a_{2}+a_{3}+\ldots+a_{n}\right) / \mathrm{N}}
\end{aligned}
$$

i.e. it is a mean value calculated over multiple time points. Thus, rms DBA cannot be used to accurately measure behaviour durations because it results in the elongation of behaviour duration. Furthermore, the high-pass filtering techniques used by Spivey \& Bishop (2013) to derive dynamic acceleration could overestimate behaviour duration (cf. the DBA method (Shepard et al. 2008)) before rms DBA is even calculated. Furthermore, the measure of body acceleration: total acceleration variability (Weippert et al. 2013) cannot be used to accurately measure behaviour durations because, as with rms DBA, each value is a mean calculated over multiple time points. Thus, total acceleration variability also results in the elongation of behaviour duration.

Possibly the most accurate way to measure behaviour duration (without video recordings and/or Hall sensor recordings of animal behaviour) is to calculate a 'partial' DBA (DBAbehav) using a running mean (moving average) of ca. 5 to 15 data points (ca. 0.2 to $0.6 \mathrm{~s}$ ) when recording at $25 \mathrm{~Hz}$. An automated system (BEnergetix - see below) is then able to accurately mark the start and end point of each behaviour within a 'DBAbehav' trace, validated for scallops Pecten maximus and Chlamys islandica, signal crayfish Pacifastacus leniusculus ${ }^{\underline{1}}$, shore crabs

\footnotetext{
19merican signal crayfish are amphibious. We have observed them moving over rough terrain, and climbing up and burrowing through brickwork. In a secure courtyard open to the sky (The Quad, Michael Smith Building, University of Manchester, UK), AXY-2 data logger-instrumented signal crayfish ( $\mathrm{n}=11$ male, 11 female) climbed out of vertical-sided aquaculture tanks containing food and walked 83 to $465(\bar{X}=223) \mathrm{m} \mathrm{d}^{-1}$ overland (recording duration $72 \mathrm{~h}$ ). Furthermore, they survived on land for up to $2 \mathrm{wk}$. In addition, over 5 non-consecutive days in 2013, we opportunistically observed signal crayfish ( $\mathrm{n}=12$ male, 8 female) leaving a lake $\left(53.1822^{\circ} \mathrm{N}, 2.0582^{\circ} \mathrm{W}\right)$ and walking overland to other water bodies around Danebridge, UK (all crayfish subsequently captured and killed). We believe this is the first scientific corroboration of observations from fish farms and infested ponds that large numbers of 'invasive' signal crayfish can escape and disperse between patchy freshwater habitats overland (e.g. Danebridge Fisheries, UK; Radcliffe Angling Club, UK, pers. comm.)
} 

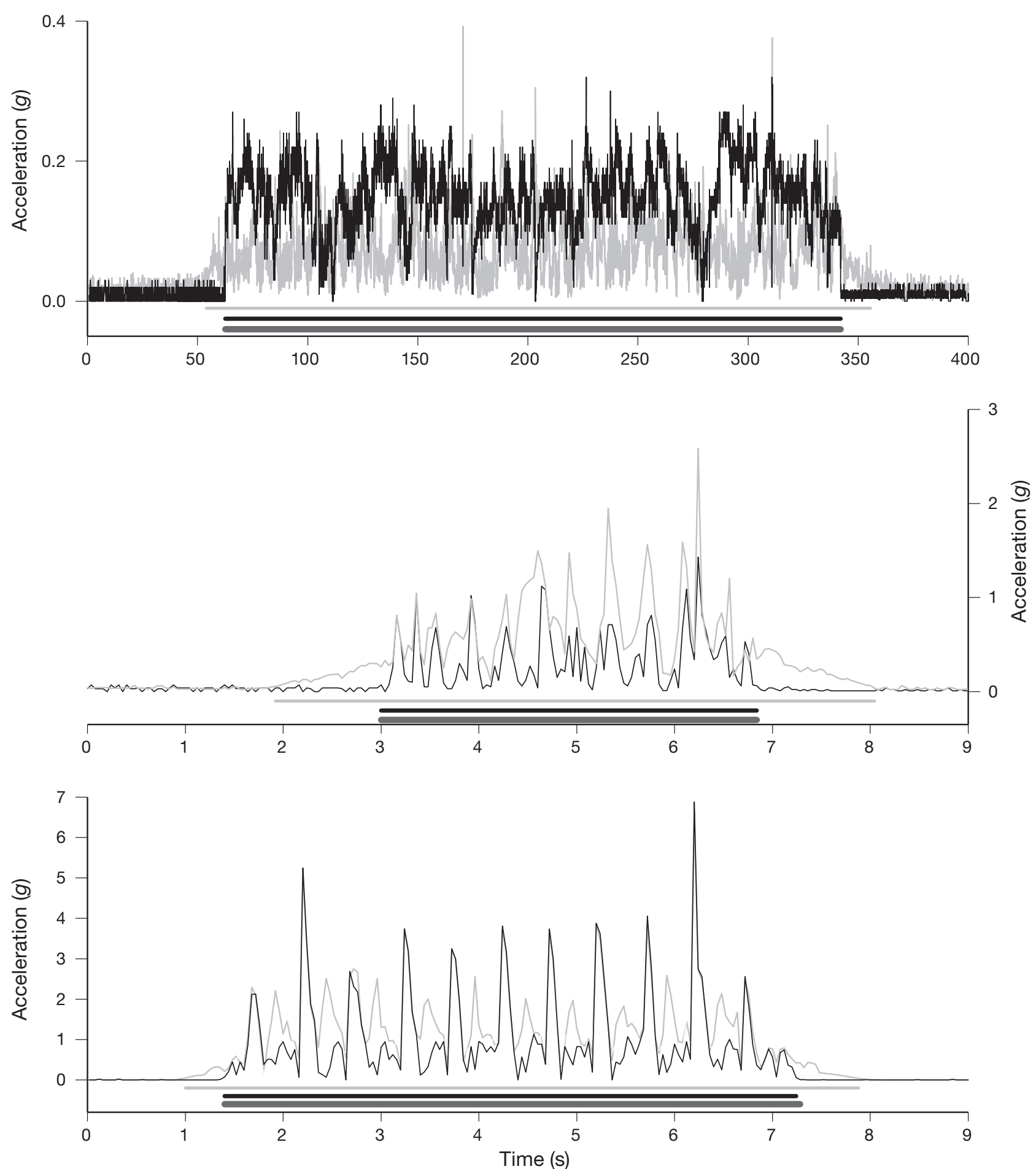

Fig. 2. Examples of the elongation of behaviour durations by vectorial summation of scallop dynamic body acceleration (VeDBA) (light grey line) derived using 'the DBA method' species/behaviour-specific running mean shown by simultaneously plotting sum absolute raw acceleration ((absolute surge + absolute sway + absolute heave) - 1) (black line). Top panel: a signal crayfish Pacifastacus leniusculus walking, i.e. invading overland for 279 s (running mean = 10 s). Middle panel: a scallop Pecten maximus spinning for $3.84 \mathrm{~s}-$ multiple consecutive rotations (running mean $=3 \mathrm{~s}$ ). Lower panel: an adult female hominid Homo sapien star jumping (10 consecutive star jumps) for $5.84 \mathrm{~s}$ (running mean = $1 \mathrm{~s}$ ). All data recorded at $25 \mathrm{~Hz}$ using an AXY-2 data logger (TechnoSmArt). The length of the horizontal lines below the acceleration traces in each panel indicate behaviour duration estimated from VeDBA (light grey line), actual behaviour duration (calculated manually (by eye) from the raw acceleration trace) (black line) and behaviour duration estimated using BEnergetix (dark grey line) 
Carcinus maenas and humans Homo sapiens. Furthermore, DBAbehav and DBA are calculated simultaneously (these data are aligned). Using the behaviour markers, the 'actual' DBA trace for each behaviour is selected and the duration of the behaviour is calculated (Fig. 2), along with the mean DBA (Supplement 1).

Publications reviewed in Brown et al. (2013) report on custom-written computer programs for the analysis of animal acceleration data. However, as far as we are aware, currently these programs are still in their infancy and, we think, could be improved by more accurately calculating behaviour duration and detecting all behaviours. For example, the semantic annotation and activity recognition system (Gao et al. 2013) could be improved by processing data recorded at high sampling frequencies (e.g. 25 to $100 \mathrm{~Hz}$ ), to discern all behaviours (Robson et al. 2009), over weeks or months. Furthermore, behaviour duration cannot be calculated accurately when acceleration is measured in blocks of $3 \mathrm{~s}$ (ShamounBaranes et al. 2012), especially when behaviour durations are short, e.g. <10 s. Automatic animal behavioural classification of acceleration data using the k-nearest neighbour algorithm (Bidder et al. 2014) can be much improved by analysing behaviours of short duration because, as this report highlights, shellfish (invertebrate) and human (vertebrate) behaviours can frequently be $<1$ to $10 \mathrm{~s}$ in duration.

We have now written a freely available $\mathrm{R}(\mathrm{R}$ Development Core Team 2013) package, BEnergetix (Mansfield \& Robson 2013), utilising the package Rcpp (v.0.10.6) to optimise large data set analysis (see Supplement 2 at www.int-res.com/articles/suppl/ b021p121_supp.pdf). BEnergetix is easy for accelerometry beginners to use to quickly calculate behavioural time-energy budgets from acceleration, metabolic rate and environmental data. The beta version of BEnergetix, its algorithms and a user manual are freely available from Mansfield \& Robson (2013). BEnergetix analyses large data sets recorded at high frequency (e.g. $100 \mathrm{~Hz}$ ) limited only by available computer memory (RAM), although future releases will seek to remove this limitation (cf. Sakamoto et al. 2009, Nathan et al. 2012, ShamounBaranes et al. 2012, Gao et al. 2013). In conclusion, the overestimation of the duration of behaviours naturally causes errors in the calculations of behavioural time-energy budgets for all species that move intermittently. Furthermore, behaviours of any duration should be accurately detected, quantified and, when appropriate, the behaviour type should be identified.
Acknowledgements. Thank you to Dr Lewis Halsey and 8 anonymous referees for helpful comments on the manuscript. Thanks also to Lydia Robertson, Dr Keith White, the IUEM dive team and Danebridge Fisheries, UK. A.A.R was supported by the 'Laboratoire d'Excellence' LabexMER (ANR10-LABX-19), co-funded by a grant from the French government under the program 'Investissements d'Avenir' and co-funded by a grant from the University of Manchester, UK.

\section{LITERATURE CITED}

Bidder OR, Campbell HA, Gómez-Laich A, Urgé P and others (2014) Love thy neighbour: automatic animal behavioural classification of acceleration data using the k-nearest neighbour algorithm. PLoS ONE 9:e88609

> Brown DD, Kays R, Wikelski M, Wilson R, Klimley AP (2013) Observing the unwatchable through acceleration logging of animal behavior. Anim Biotelemetry 1:20

$>$ Gao L, Campbell HA, Bidder OR, Hunter J (2013) A webbased semantic tagging and activity recognition system for species' accelerometry data. Ecol Inform 13:47-56

Gleiss AC, Wilson RP, Shepard ELC (2011) Making overall dynamic body acceleration work: on the theory of acceleration as a proxy for energy expenditure. Method Ecol Evol 2:23-33

Halsey LG, White CR (2010) Measuring energetics and behaviour using accelerometry in cane toads Bufo marinus. PLoS ONE 5:e10170

Mansfield RP, Robson AA (2013) BEnergetix: an R package to calculate behavioural time-energy budgets from acceleration, metabolic rate and environmental data. https:// drive.google.com/folderview?id=0B8JNUcOcQVpgQjJz WVBBUkg0Q2c\&usp=sharing \&tid=0B8JNUcOcQVpg NWI3eHBmckEwZXM

> Nathan R, Spiegel O, Fortmann-Roe S, Harel R, Wikelski M, Getz WM (2012) Using tri-axial acceleration data to identify behavioral modes of free-ranging animals: general concepts and tools illustrated for griffon vultures. J Exp Biol 215:986-996

R Development Core Team (2013) R: a language and environment for statistical computing. R Foundation for Statistical Computing, Vienna

> Robson A, Wilson R, Garcia de Leaniz C (2007) Mussels flexing their muscles: a new method for quantifying bivalve behaviour. Mar Biol 151:1195-1204

> Robson AA, Thomas GR, Garcia de Leaniz C, Wilson RP (2009) Valve gape and exhalant pumping in bivalves: optimization of measurement. Aquat Biol 6:191-200

$>$ Robson AA, Chauvaud L, Wilson RP, Halsey LG (2012) Small actions, big costs: the behavioural energetics of a commercially important invertebrate. J R Soc Interface 9: 1486-1498

Sakamoto KQ, Sato K, Ishizuka M, Watanuki Y, Takahashi A, Daunt F, Wanless S (2009) Can ethograms be automatically generated using body acceleration data from freeranging birds? PLoS ONE 4:e5379

> Shamoun-Baranes J, Bom R, van Loon EE, Ens BJ, Oosterbeek K, Bouten W (2012) From sensor data to animal behaviour: an oystercatcher example. PLoS ONE 7: e37997

Shepard ELC, Wilson RP, Halsey LG, Quintana F and others (2008) Derivation of body motion via appropriate smoothing of acceleration data. Aquat Biol 4:235-241

Spivey RJ, Bishop CM (2013) Interpretation of body- 
mounted accelerometry in flying animals and estimation of biomechanical power. J R Soc Interface 10:20130404 Weippert M, Stielow J, Kumar M, Kreuzfeld S, Rieger A, Stoll R (2013) Tri-axial high-resolution acceleration for oxygen uptake estimation: validation of a multi-sensor device and a novel analysis method. Appl Physiol Nutr Metab 38:

Editorial responsibility: J. Rudi Strickler, Milwaukee, Wisconsin, USA
345-351

> Wilson RP, White CR, Quintana F, Halsey LG, Liebsch N, Martin GR, Butler PJ (2006) Moving towards acceleration for estimates of activity-specific metabolic rate in freeliving animals: the case of the cormorant. J Anim Ecol 75: 1081-1090

Submitted: January 15, 2014; Accepted: May 6, 2014 Proofs received from author(s): June 24, 2014 